\title{
Onde estão os homens? O que os distanciam ou os aproximam dos serviços da atenção primária à saúde
}

\section{Where are the men? What keep them away or approach them to the primary health care}

Kelly Oliveira Santos ${ }^{1}$, Edirlei Machado dos-Santos ${ }^{2}$

\section{Resumo}

Os homens não possuem comumente hábitos de práticas preventivas. Logo, ouvi-los tornou-se imprescindível para compreender as suas concepções que justificam tais atitudes. O presente estudo teve como objetivos identificar os motivos que os levam a procurar atendimento nos serviços da Atenção Primária à Saúde, e compreender os motivos que os afastam dos serviços da Atenção Primária à Saúde. Trata-se de um estudo de caso qualitativo, exploratório e descritivo. Participaram da pesquisa treze homens residentes no município de Vitória da Conquista (Bahia), na faixa etária de 25 a 59 anos. Os dados foram coletados por meio de entrevistas semiestruturadas e analisados por meio da técnica de Análise de Conteúdo Temática. Os resultados mostraram a forma como os homens concebem a saúde e como isto reflete em suas atitudes em relação à busca pelos serviços de saúde. Revelou também os fatores da aproximação e do afastamento do público masculino no cenário da Atenção Primária à Saúde que envolve concepções culturais e até mesmo questões institucionais. Portanto, o resultado deste estudo pode subsidiar os profissionais no desenvolvimento de estratégias para estimular e acolher a população masculina, considerando as limitações e barreiras singulares que este público apresenta.

Palavras chave: Saúde do homem. Atenção primária à saúde. Gênero e saúde.

\begin{abstract}
Men usually don't have preventive habits. Thus, listening to them is necessary to understand the conceptions they have that justify their attitudes. This study is focused on identifying the reasons that make men look for Primary Health Care and to understand the reasons that keep them away or approach them. This is a qualitative, exploratory and descriptive case study. Thirteen men aged 2559 years old, who live in Vitória da Conquista city, participated in the study. The data was collected by semi-structured interviews and was analyzed by Thematic Content Analysis. The results showed how men understand health and how their perception reflects the way they are looking for health services. The study also showed the reasons why men approach or keep away from Primary Health Care, including cultural conceptions and even institutional issues. The results of the study support the development of strategies that could stimulate and welcome the male population, in spite of the limitations and natural barriers that this group contains.
\end{abstract}

Keyword: Men's health. Primary health care. Gender and health.

\footnotetext{
${ }^{1}$ Enfermeira pela Universidade Federal da Bahia (UFBA), Bahia, Brasil.

${ }^{2}$ Doutorado em Enfermagem pela Universidade Estadual de Campinas. Professor Adjunto da Universidade Federal do Mato Grosso do Sul; Três Lagoas, Mato Grosso do Sul, Brasil. E-mail: edirlei.machado@ufms.br
} 


\section{Introdução}

A relação dos homens com os serviços da Atenção Primária à Saúde (APS) ${ }^{1 *}$ vem sendo objeto de estudo de alguns pesquisadores (COUTO et al., 2010; FIGUEIREDO, 2005; GOMES et al., 2011). Nestes serviços destaca-se a presença ínfima masculina, atrelado a isso, problematiza-se a vulnerabilidade destes homens o que torna esta situação um importante problema de saúde pública.

Dados do Sistema de Informação sobre Mortalidade (SIM), do Ministério da Saúde, de 2010, mostram que $31,1 \%$ dos óbitos por todas as causas ocorreram na faixa etária de 20 a 59 anos, com predominância na população masculina $(68,2 \%)$, sendo que a taxa específica de mortalidade dos homens foi o dobro da taxa observada para as mulheres (BRASIL, 2012c). Muitas destas mortes poderiam ser evitadas se os homens estivessem mais presentes no cenário dos serviços de saúde.

A forma de organização do sistema de saúde no Brasil privilegia grupos populacionais considerados mais vulneráveis, por meio de ações programáticas voltadas para a saúde da mulher, da criança e do idoso, com discreta ênfase às ações de atenção à saúde do homem (SILVA et al., 2012).

Muitas são as suposições e justificativas acerca do reduzido envolvimento de homens com os cuidados em saúde, sejam estas referentes ao autocuidado, sejam relacionadas à busca por cuidados especializados (FIGUEIREDO, 2005). Vincula-se à problemática, o fato de a população masculina adentrar aos serviços de saúde com um quadro clínico de morbidade já instalado (SILVA et al., 2013).

Outro aspecto refere-se à estrutura organizacional das unidades de saúde que pouco contribui para a presença masculina, uma vez que o funcionamento destes serviços ocorre em horários comerciais o que coincide com o horário das atividades laborais do público masculino (GOMES et al., 2011).

Desta forma, torna-se necessário um olhar direcionado, uma escuta atenta e técnica aos fatores que influenciam os comportamentos dos homens no tocante ao cuidado e à procura de assistência à saúde, para que deste modo, os profissionais de saúde possam pensar medidas mais efetivas para atrair e atender as

1 *Na presente pesquisa os termos Atenção Primária à Saúde e Atenção Básica foram utilizados como sinônimos para designar o primeiro nível de atenção dos serviços públicos de saúde no Brasil. especificidades do público masculino, no sentido de colaborar com a melhoria de sua saúde (SILVA et al., 2012).

Neste contexto, identificar as circunstâncias que aproximam os homens e que também os afastam dos serviços da Atenção Primária à Saúde torna-se necessário para propor estratégias que viabilizem o acesso dos homens aos serviços de saúde, tendo por meio deste a garantia da assistência em uma perspectiva da integralidade em saúde.

Diante do exposto, o presente trabalho teve como objetivos identificar os motivos que levam os homens a procurarem atendimento nos serviços da Atenção Primária à Saúde, e compreender os motivos que os afastam dos serviços da Atenção Primária à Saúde.

\section{Material e Método}

Trata-se de um estudo de caso qualitativo (MINAYO, 2007) de natureza exploratória e descritiva. A pesquisa foi desenvolvida no município de Vitória da Conquista, localizado na região sudoeste da Bahia. E buscou responder as seguintes questões norteadoras: Quais são as situações que levam os homens a procurar pelos serviços de saúde? Por que os homens não têm buscado pelos serviços da Atenção Primária á Saúde?

A amostra foi determinada pelo critério de saturação teórica. O fechamento da amostra por saturação teórica nada mais é do que a suspensão de novos participantes quando não se obtém mais dados novos, ou seja, quando há uma repetição dos dados não há necessidade de persistir na coleta de dados (FONTANELLA; RICAS; TURATO, 2008). Portanto, a amostra desta pesquisa apresentou uma saturação teórica com a realização de 13 entrevistas.

Para a coleta de dados, a técnica empregada foi a entrevista individual semiestruturada, na qual os pesquisadores utilizaram-se de um roteiro. $\mathrm{O}$ roteiro foi composto por duas partes, sendo a primeira constituída de questões objetivas que possibilitaram fazer uma caracterização do perfil sociodemográfico dos participantes do estudo e a segunda parte com questões que nortearam o desenvolvimento da pesquisa. A realização das entrevistas foi agendada previamente com os participantes da pesquisa, e o contato com eles foi intermediado pelas Agentes Comunitárias de Saúde. O local e horário da realização das entrevistas foram combinados previamente entre participantes e entrevistador, de modo que as entrevistas aconteceram em locais, dias e horários mais apropriados aos participantes do estudo. As entrevistas duraram em 
torno de 10 minutos e foram gravadas para que nenhum dado fosse perdido, o que também facilitou o processo de transcrição das falas.

Os critérios de inclusão levados em consideração para os homens participarem da pesquisa foram: ter idade entre 25 e 59 anos, por ser esta a mesma que a Política de Atenção Integral à Saúde do Homem traz como prioridade; e concordar em participar da pesquisa e assinar o Termo de Consentimento Livre e Esclarecido (TCLE).

Após transcrição do conteúdo obtido, procedeu-se a análise dos dados por meio da técnica de Análise de Conteúdo na modalidade Temática, segundo a proposta de Minayo (2007) que será apresentada a seguir. Para organização da análise dos dados qualitativos foram seguidas três etapas operacionais.

A primeira, denominada de pré-análise, consistiu em um contato profundo e exaustivo com as transcrições por meio de repetidas leituras do material, no intuito de se garantir algumas normas de validade, sendo estas, exaustividade, representatividade, homogeneidade e pertinência.

Em um segundo momento, realizou-se a exploração do material, de modo a alcançar o núcleo de compreensão textual. Para isso, buscou-se de acordo o conteúdo das falas a categorização, que consistem em um processo de redução do texto em palavras e expressões significativas.

E por fim, realizou-se as interpretações qualitativas dos dados, articulando-as com o quadro teórico abordado inicialmente, bem como, a abertura para novas visões interpretativas (MINAYO, 2007).

Para o desenvolvimento deste estudo, o projeto de pesquisa foi submetido à apreciação do Comitê de Ética em Pesquisa (CEP) do Instituto Multidisciplinar em Saúde (IMS) da Universidade Federal da Bahia (UFBA), sendo este aprovado sem restrições (C.A.A.E: 27332914.3.0000.5556).

A identificação das entrevistas de cada participante foi feita pelo uso da letra alfabética ' $E$ ' de entrevistado, acrescido de números, segundo a sequência que cada entrevista foi realizada.

\section{Resultados}

Participaram da pesquisa treze homens no grupo etário entre 25 a 59 anos. Apenas dois participantes não estão ativos no mercado de trabalho, e dos que exercem atividades laborais todos possuem uma jornada de trabalho de no mínimo oito horas diárias, sendo que a maior corresponde a quatorze horas. Quatro referiram trabalhar nos turnos diurno e noturno por ter algum tipo de estabelecimento próprio, outros três trabalham somente à noite, outros três em horário comercial e apenas um referiu trabalhar nos turnos vespertino e noturno. A renda mensal familiar variou entre um e cinco salários mínimos. Em relação ao grau de instrução formal dos participantes um não apresentou escolaridade, cinco possuem ensino fundamental incompleto, um apresentou ensino médio incompleto e seis, ensino médio completo. Dois responderam que nunca procuraram a unidade de saúde, dois vão pelo menos uma vez ao ano, seis disseram que só procuram a unidade de saúde quando precisam e outros três referiram procurá-la com maior frequência.

Foram construídas duas categorias temáticas: Homens e suas percepções sobre saúde e as barreiras na busca pelos serviços de saúde e Elementos que estimulam a busca dos homens pelos serviços de saúde.

Abaixo são apresentados os fragmentos das falas que geraram a Categoria Temática 1:

Acho que é estar com o corpo todo funcionando bem, sem nenhum tipo de problema, doença, dor. [E1]

Por doença. Assim, se tiver algum problema. [...] Eu vou lá é pra saber se a pressão tá alta. Eu vou quando sinto que ela [a pressão arterial] está alta. [E6]

Por doenças. Sem sentir nada eu não vou não. Só vou [à unidade de saúde] quando estou sentindo mesmo. [E9]

Saúde é não ter dor de cabeça, nenhum tipo de dor, não ter doenças. [E13]

Acho que é porque eu não sinto dor nenhuma, [...] é porque a cultura dos homens brasileiros é essa ai, só procura o médico quando adoece, quando está sentindo alguma coisa, infelizmente é verdade, infelizmente. [...] Eu estou me sentindo bem, não vejo necessidade de estar nesses lugares. [...] [E13]

Quando se trata de saúde é você estar bem tanto fisicamente quanto mentalmente. [E10]

Saúde é tudo. Está com saúde é estar bem consigo mesmo, você estando bem é o mais importante. Se você pratica uma atividade fisica é melhor ainda, tem um lazer, tudo isso é saúde. [E5]

Saúde pra mim é ter uma qualidade de vida 
Santos, K. O.; Dos-Santos, E. M.

boa, se você não tem saúde não tem como ter uma boa qualidade de vida. Qualidade de vida econômica abrange essas coisas do lazer, passeio. [E12]

Eu fico com medo, eu penso assim você vai procurar um posto de saúde ai pronto começam a vim os problemas, muitos problemas, eu fico com isso na minha cabeça e parece que vai acontecer não sei, parecem que eu vou ficar doente. Eu tenho medo até de fazer um exame. Eu tenho cisma de fazer exame e vim mais problemas. [E4]

Se eu vou a uma unidade de saúde ou hospital o médico vai passar um exame para mim, eu vou e faço. Aí o cara fala você tem isso tem aquilo ai eu vou morrer muito mais cedo. Eu me sinto muito mais preparado estando do jeito que estou do que a pessoa vim me falar que eu tenho problema [...]. Eu acho que se eu souber que eu tenho alguma coisa eu fico muito mais doente do que eu não saber. [E10]

$E u$, meu pai, meus irmãos, a minha família é desse jeito [não busca pelos serviços de saúde por medo]. Todos os homens da familia foram criados desse jeito, com esse pensamento [...] Minha mãe morreu de câncer, todos os irmãos dela morreram de câncer, eu fico com medo. [E10]

A minha dificuldade hoje, que mais dificulta para mim é justamente aqui, é sair do trabalho. [E2]

Eu não vou porque o meu trabalho não permite. É ruim demais, isso aqui, eu estou numa prisão [...] [E5]

O tempo que a gente não tem, meu tempo é curto. Só pra você ter ideia eu não tive tempo de ir tomar a vacina. E olha que teve aqui do lado, na creche, eu tomo porque sou diabético. Minha vida é uma correria. [E11] Não sei se existe azar, mas se existir eu sou azarado ou existe uma marcação comigo neste posto, que inclusive eu já fui muito maltratado ali, a parte do ambulatório do posto é precária, a gente vê as instalações bonitas, mas não vê o mais importante que é o atendimento. [...] Não consigo ser atendido. E por motivo de ter a minha vida tão corrida eu não tenho disponibilidade de ficar indo várias vezes insistindo, persistindo, eu não tenho. [E3]

Pela demora em ser atendido. O problema é justamente esse aí. É a dificuldade em ser atendido. Porque se a gente chegasse lá e fosse atendido... Mas a dificuldade é essa aí. [E7]

Só quando é assim, uma dor de cabeça básica, algumas coisas assim. [E9]

Só tomo alguns remédios assim, esses de dor de cabeça, de gripe, febre, outros remédios não. [E12]

Eu me automedico mesmo. Se sinto alguma coisa tomo logo remédio [...] [E13]

Vou à farmácia. Eu tenho um colega que é ótimo. [...] Eu sentia uma dor de cabeça forte mesmo, tomava todos os tipos de comprimido e não melhorava, aí eu falei com esse colega meu ele me indicou um comprimido. É só tomar e pronto. A dor some. [...] O cara é bom mesmo. [E11]

Porque eu acho que é lá que está o atendimento mais certo né. Posto é só pra praticamente encaminhar para os exames. Não vai ter aquele atendimento que você está precisando na hora ali da dor. [E5] $O$ hospital tem mais preparo, dependendo do caso que você está sentindo. Se for o caso de vômito, hemorragia, você tem que procurar um hospital, não vai procurar um posto. Dependendo do horário também, se for de manhã. Têm vezes que o hospital está cheio, aí você vai a outro não encontra, ai você vai no posto de saúde, de último caso você vai no posto de saúde.[E8]

Os recortes das falas a seguir possibilitou a geração dos núcleos de sentido da Categoria Temática 2:

Toda vez que eu vou lá [unidade de saúde da família] foi tudo ok. Por sinal a menina que atende lá na recepção muito carismática ela, se preocupa em atender a gente na maior receptividade. É tão bom quando somos bem atendidos, dá vontade de voltar. Hoje tudo é na base do diálogo. Se não tiver diálogo, não adianta. [E8]

[...] não é porque eu estava sentindo alguma coisa, é porque aquele exame de rotina sabe, exame de urina, de sangue. Até porque eu faço minha parte, eu sou doador de sangue. 
E aí eu me preocupo muito, e eu sempre faço isso para eu ver como está. [E2]

Eu acho que é importante [procurar a unidade de saúde] errado é não ir. $O$ errado sou eu, deveria ter mais cuidado com a minha saúde, com a prevenção. [...] Costumo fazer aqueles exames de rotina, só mais de prevenção mesmo. Vou uma vez por ano, às vezes passa de um ano. Mas geralmente eu faço. Geralmente consulta, aquele negócio que teve do glaucoma, eu fiz, em nível de prevenção, porque eu tenho irmã que tem, aí eu fiz. [E12]

Antes, até eu não sentir um problema mais grave eu não procurava não, só no último caso mesmo. Hoje, eu já procuro, às vezes pra fazer um exame de rotina assim, exame de sangue, pra saber como está. [...] Pelo menos que eu lembro assim, é de um ano e meio, dois anos no máximo. [E5]

Sempre eu vou sempre eu tô lá. Inclusive sempre os médicos passam ai [no domicílio]. Hoje mesmo eu vou fazer um exame que o médico passou o pedido, e já chegou. [...] É que eu tenho câncer de pele, eu to sempre lá também porque eu tomo remédio controlado. Às vezes nem trocar receita eu vou, eu vou logo falar com ele [médico]. [E6]

\section{Discussão}

CATEGORIA TEMÁTICA 1: Homens e suas percepções sobre saúde e as barreiras na busca pelos serviços de saúde

Previamente à discussão acerca das barreiras identificadas pelos homens participantes do presente estudo buscou-se conhecer suas percepções sobre saúde, no sentido de correlacioná-las com os motivos que os afastam dos serviços de saúde, especificamente, a Estratégia Saúde da Família.

Sobre as barreiras de acesso dos homens participantes deste estudo aos serviços da Atenção Básica, estas puderam ser agrupadas em aspectos que se referem: à visibilidade dada aos aspectos curativos; ao medo da constatação de adoecimento; à falta de tempo; dificuldades em ser atendido no mesmo dia que busca pelos serviços e; à necessidade imediatista de resolução de seu problema de saúde.

O significado de saúde é reflexo da conjuntura social, econômica, política e cultural. Portanto, saúde não representa a mesma coisa para todas as pessoas. Dependerá de uma gama de fatores que envolvem a época, o lugar, a classe social, os valores individuais e as concepções científicas, religiosas, filosóficas (SCLIAR, 2007).

Por envolver diversas dimensões, estabelecer um conceito de saúde é bastante complexo, no entanto, a compreensão deste fenômeno e a percepção que os homens têm em relação ao seu significado tornam-se importantes na busca pelas respostas que implicam na procura pelos serviços de saúde da Atenção Básica, especificamente, a Estratégia Saúde da Família.

A percepção de saúde entendida como ausência de doença é largamente difundida no senso comum (BATISTELLA, 2007). Neste contexto, considera-se que a percepção é sempre uma experiência dotada de significação, isto é, o percebido é dotado de sentido e tem sentido em nossa história de vida, fazendo parte de nosso mundo e de nossas vivências (CHAUÍ, 2012). Alguns dos entrevistados relataram possuírem saúde a partir da constatação da ausência de sintomas, o que os remetem a ideia de que a procura pelos serviços de saúde não se faz necessária.

Nesta perspectiva, alguns homens participantes do estudo, ao mesmo tempo em que trazem a ausência de doença como forma de conceber saúde, implicitamente trazem na fala uma das barreiras de acesso aos serviços da Atenção Primária à Saúde, ou seja, o conceito de saúde pautado em um modelo curativista de atenção gera certa invisibilidade às ações de prevenção de doenças e de promoção da saúde na percepção dos entrevistados.

Atrelada à situação anterior, isto é, a percepção de saúde como ausência de doença, os homens têm dificuldade de reconhecer suas necessidades, cultivando o pensamento mágico de que não adoecem (BRASIL, 2008). A maioria deles acredita que se não apresenta nenhum sintoma clínico, logo, não necessita buscar pelos serviços de saúde.

Neste contexto, a proposta da Política Nacional de Atenção Integral à Saúde do Homem é a de transformar os aspectos culturais inerentes ao público masculino, valorizando as ações de prevenção. Enfatizando, para isso, uma modificação do paradigma da percepção masculina sobre os cuidados com a sua saúde, suas motivações e empecilhos para fazer a prevenção de doenças (ALVES et al., 2011).

Um participante associou sua percepção sobre saúde ao conceito definido pela Organização Mundial de Saúde (OMS) na década de 1940, ou seja, em que 
saúde é definida como um completo estado de bemestar físico, mental e social, e não apenas a ausência de doença ou enfermidade (BATISTELLA, 2007).

Neste contexto, alguns homens apresentaram uma percepção mais acurada sobre saúde, que tem relação àquele formulado durante a VIII Conferência Nacional de Saúde, conhecido como conceito ampliado de saúde. Este novo conceito elabora um sentido mais amplo, tendo a saúde como determinantes e condicionantes, entre outros, a alimentação, a moradia, o saneamento básico, o meio ambiente, o trabalho, a renda, a educação, a atividade física, o transporte, o lazer e o acesso aos bens e serviços essenciais (BRASIL, 1990).

Outro aspecto que contribui para o distanciamento dos homens dos cenários das unidades de saúde da Atenção Básica refere-se ao medo da descoberta de alguma doença. Deste modo, alguns homens referiram temer a descoberta de alguma patologia e por isso se afastam dos serviços de saúde.

$\mathrm{O}$ fato de lidar com o homem adoecido mexe muito com o seu aspecto psicológico, pois, a doença para eles é considerada como sinal de fragilidade, e o processo de adoecimento para os homens não é compreendido como inerente à sua própria condição sociopsíquica e biológica (BRASIL, 2008).

Ademais, o aspecto cultural, medo da constatação da doença, pode ser em algumas circunstâncias potencializado quando o homem tem histórico de alguma doença em outros membros da família e que esta tem o histórico familiar como fator de risco para o seu desenvolvimento.

Soma-se a isso, o fato deles referirem a falta de tempo por não poder deixar seus trabalhos para irem à unidade de saúde em busca de atendimento. Nesta vertente, os horários de funcionamento das unidades coincidem com as jornadas laborais dos trabalhadores. Tal situação dificulta o atendimento de usuários do sexo masculino, culturalmente os provedores da família e a referência como trabalhadores (SCHRAIBER et al., 2010).

A ausência dos homens nos serviços de Atenção Primária à Saúde ainda pôde ser percebida a partir do modo como o atendimento é dispensado pela equipe da Estratégia Saúde da Família, uma vez que na percepção dos homens, estes esbarram em dificuldades que fragilizam seu atendimento quando da procura pela unidade. $\mathrm{O}$ fator trabalho associado a uma ida à unidade e não receber atendimento é algo que contribui para que ele não retorne aos serviços de saúde.

Em decorrência do distanciamento da unidade de saúde pelos distintos motivos que dificultam seu acesso aos serviços, um aspecto constatado em algumas falas refere-se à busca de meios alternativos diante de algum problema de saúde, destacando a automedicação feita por alguns homens.

Em relação aos fatores que afastam os homens participantes da pesquisa dos serviços da Estratégia Saúde da Família, relacionam-se a busca por serviços que lhes dêem respostas mais rápidas e objetivas acerca do que eles procuram como farmácias ou prontos-socorros. Nesses lugares, os homens seriam atendidos mais rapidamente e conseguiriam expor seus problemas com mais facilidade (FIGUEIREDO, 2005).

Apresentando complicações, os homens recorrem aos serviços de urgência e emergência e fazem deste serviço sua porta de entrada para o sistema público de saúde. Sendo as unidades hospitalares as preparadas para receberem este homem em estado grave e que vão atuar de maneira curativista, fica a lógica para os homens de que os serviços hospitalares são os mais eficazes por conta de ser um serviço com resultados atingidos em curto prazo de tempo.

Diante do contexto apresentado, os homens deixam de se beneficiar das ações de promoção da saúde e prevenção das doenças e deslocam-se para os serviços de pronto atendimento, superlotando-os muitas vezes com demandas que poderiam ser sanadas na atenção básica (FERREIRA, 2013).

$\mathrm{O}$ reconhecimento de que os homens adentram o sistema de saúde por meio da atenção especializada tem como consequência o agravo da morbidade pelo retardamento na atenção e maior custo para o Sistema Único de Saúde (SUS). É necessário fortalecer e qualificar a Atenção Primária à Saúde garantindo, assim, a promoção da saúde e a prevenção aos agravos evitáveis (BRASIL, 2008).

De fato, pôde-se observar com a discussão dos dados desta categoria temática que distintos são os fatores que contribuem para distanciar a população masculina dos serviços de saúde da Atenção Básica. A percepção que cada participante da pesquisa apresentou sobre saúde também é fator inerente a presença ínfima dos homens nos serviços de Atenção Primária à Saúde.

\section{CATEGORIA TEMÁTICA 2: Elementos que estimulam} a busca dos homens pelos serviços de saúde

Que os homens procuram menos do que as mulheres pelos serviços de saúde é um fato de destaque na literatura nacional e internacional (GOMES, 2008). 
Tais motivos inerentes ao grupo estudado nesta pesquisa foram apresentados na categoria temática anterior. Portanto, faz-se necessário conhecer os motivos que os aproximam dos serviços da Estratégia Saúde da Família. Identificar estes aspectos torna-se imprescindível para compreender a realidade singular da população masculina estudada.

O cuidado na Atenção Básica deve ser baseado nos princípios do acolhimento e da escuta qualificada à população, aliado à gestão local reflexiva e às boas práticas de atenção, de forma a garantir um atendimento humanizado, resolutivo e que propicie a criação de vínculo entre as equipes da Atenção Básica e as pessoas, legitimando este ponto como a porta de entrada prioritária e preferencial para as redes de atenção à saúde do SUS (BRASIL, 2012b).

$\mathrm{O}$ acolhimento deve estar incorporado ao processo de trabalho das equipes de saúde da família e constitui elemento fundamental para emanar o vínculo entre o trabalhador de saúde e o usuário/famíla. "Trata-se de uma postura de escuta com compromisso de dar uma resposta às necessidades de saúde trazidas pelo usuário" (GARUZI et al., 2014, p. 146).

Apesar de alguns homens do estudo falarem que pouco frequentam os serviços da Atenção Primária à Saúde, alguns destes homens reconhecem a importância da prevenção, e a relevância de buscarem atendimento que envolve as ações de prevenção de doenças e promoção da saúde.

Nesta perspectiva, alguns homens relataram que passaram a valorizar as ações de prevenção oferecidas pelas unidades de saúde a partir da maturidade adquirida com o acréscimo da idade cronológica, passando deste modo a procurar os serviços para as ações de prevenção e promoção.

Um aspecto que foi identificado como elemento de aproximação dos homens com os serviços da Estratégia de Saúde da Família refere-se ao fato de o usuário ser portador de alguma doença crônica, haja vista que a própria condição de ser portador de doença crônica remete ao modelo biomédico de atenção à saúde que grande parte dos homens tem acerca do processo saúde-doença, discutido na categoria temática anterior.

A doença como principal fator aproximador dos homens participantes deste estudo corrobora com os dados da pesquisa que avaliou 43 gestores e 86 homens adultos de equipes de Saúde da Família contemplando as diferentes regiões (MOURA et al., 2014).

A situação anterior está implícita nas percepções dos homens participantes da pesquisa que dialeticamente reconhecem a ausência de doença como fator de distanciamento da unidade de saúde, como discutido anteriormente neste estudo, e a sua presença como fator que "exige" o comparecimento frequente do homem aos serviços de saúde da Atenção Básica.

Neste contexto, destaca-se a ocorrência da baixa acessibilidade do homem aos serviços da Atenção Básica, o que sugere sua vulnerabilidade. Desta forma, torna-se um relevante problema de saúde pública, já que a busca pelos serviços de saúde pela população masculina, quando existe, está atrelada a um quadro clínico de morbidade cronificado, onerando significativamente o SUS (SILVA et al., 2013).

Ao finalizar a discussão dos dados desta categoria temática, foi possível identificar que os homens trouxeram em suas percepções alguns aspectos que contribuem para a busca destes pelos serviços da Atenção Básica, sendo que o acolhimento dispensado pela equipe, o reconhecimento da importância das ações de prevenção e a própria condição de ser portador de alguma doença crônica é o que os aproximam dos serviços da Estratégia Saúde da Família.

\section{Considerações Finais}

Os resultados do presente estudo corroboram com os dados de outros estudos desenvolvidos acerca da relação homens serviços de saúde. A análise empreendida evidenciou que alguns homens não estão habituados a buscar pelos serviços de saúde, principalmente quando se trata de ações de prevenção de doenças.

Os depoimentos dos participantes deste estudo revelaram as concepções que os homens têm sobre saúde, sendo esta fortemente alicerçada por meio do modelo curativista, pautado pela intervenção doençacura.

Os fatores apontados pelos participantes do estudo em relação aos aspectos que dificultam o acesso aos serviços envolvem aspectos culturais e barreiras institucionais.

Estar doente é o elemento principal que leva os homens a buscar atendimento nos serviços de saúde da Atenção Primária à Saúde, sendo que alguns casos devido à gravidade do processo de adoecimento o fazem em serviços de maior complexidade da rede hospitalar, evidenciando com esta prática, a necessidade de estratégias capazes de transformar conceitos e mostrar a relevância das ações de prevenção de doenças e de promoção da saúde no âmbito dos serviços da Atenção Básica. 
No que se refere à Saúde do Homem ainda há muito a ser feito para atrair este público a estar mais presente na rede de serviços do SUS. Envolvem desde medidas estruturais e organizacionais dos serviços da Atenção Básica, até mesmo ações que visam estimular os homens para o cuidado com a sua saúde, no sentido de corresponsabilizá-los pela sua própria saúde para que seja motivado para a busca dos serviços de saúde.

Assim, conhecer os fatores que afastam os homens ou os aproximam dos serviços da Atenção Primária à Saúde tornou-se relevante, como elementos necessários à desconstrução de práticas e conceitos estereotipados que comprometem o nível de saúde da população masculina estudada.

Portanto, os resultados deste estudo poderão proporcionar aos profissionais de saúde maior subsídio para que estes, em conjunto com o público masculino e a gestão dos serviços, construam espaços para discussão, reflexão e modificação da realidade identificada, considerando o contexto que permeia tal público para instituição de ações que efetivamente promovam a saúde masculina, pautadas na qualidade de vida.

\section{Referências}

ALVES, R. F.; SILVA, R. P.; ERNESTO, M. V.; LIMA, A. G. B.; ZOUZA, F. M. Gênero e saúde: o cuidar do homem em debate. Psicologia: Teoria e Prática, São Paulo, v. 13, n. 3, dez. 2011.

BATISTELLA, C. Abordagens contemporâneas no conceito de saúde. In: FONSECA, A.; CORBO, A. D. O território e o processo saúde-doença. Rio de Janeiro: EPSJV/Fiocruz, 2007. p. 51-86.

BRASIL. Conselho Nacional de Saúde. Resolução $n^{\circ} 466$ de 12 de dezembro de 2012a. Disponível em: <http://conselho.saude.gov.br/resolucoes/2012/ Reso466.pdf $>$. Acesso em: 17 jul. 2014.

BRASIL. Lei $n^{\circ}$ 8.080, de 19 de setembro de 1990 . Dispõe sobre as condições para a promoção, proteção e recuperação da saúde, a organização e o funcionamento dos serviços correspondentes e dá outras providências. Disponível em: <http://www. planalto.gov.br/ccivil_03/leis/18080.htm>. Acesso em: 17 jul. 2014.

BRASIL. Ministério da Saúde. Secretaria de Atenção à Saúde. Departamento de Ações Programáticas Estratégicas. Política nacional de atenção integral à saúde do homem: princípios e diretrizes. Brasília,
2008. Disponível em: <http://bvsms.saude.gov.br/ bvs/publicacoes/politica_nacional_atencao_saude_ homem.pdf> Acesso em: 1 maio $201 \overline{7}$.

BRASIL. Ministério da Saúde. Secretaria de Atenção à Saúde. Departamento de Atenção Básica. Acolhimento à demanda espontânea: queixas mais comuns na atenção básica. Brasília, 2012b. Disponível em: $\quad<$ http://189.28.128.100/dab/docs/publicacoes/ cadernos_ab/caderno_28.pdf $>$. Acesso em: 1 maio 2017.

BRASIL. Ministério da Saúde. Secretaria de Vigilância em Saúde/MS. Mortalidade do adulto no Brasil: taxas de mortalidade segundo o sexo, as causas e as regiões, 2010. In: . Saúde Brasil 2011: uma análise da situação de saúde e a vigilância da saúde da mulher. Brasília, 2012c. p. 183-208.

CHAUÍ. M. Convite à filosofia. 14. ed. São Paulo: Ática, 2012.

COUTO, M. T.; PINHEIRO, T. F.; VALENÇA, O.; MACHIN, R.; SILVA, G. S. N.; GOMES, R.; SCHRAIBER, L. B.; FIGUEIREDO, W. S. O homem na atenção primária à saúde: discutindo (in)visibilidade a partir da perspectiva de gênero. Interface: Comunicação, Saúde, Educação, Botucatu, v. 14, n. 33, p. 257-70, 2010.

FERREIRA, M. C. Desafios da política de atenção à saúde do homem: análise das barreiras enfrentadas para sua consolidação. Revista Eletrônica Gestão \& Saúde, Brasília, v. 4, n. 1, p. 1833-1847, 2013.

FIGUEIREDO, W. Assistência à saúde dos homens: um desafio para os serviços de atenção primária. Ciência e Saúde Coletiva, Rio de Janeiro, v. 10, n. 1, p. 105-109, 2005.

FONTANELLA, B. J. B.; RICAS, J.; TURATO, E. R. Amostragem por saturação em pesquisas qualitativas em saúde: contribuições teóricas. Cadernos de Saúde Pública, Rio de Janeiro, v. 24, n. 1, p. 17-27, 2008.

GARUZI, M.; ACHITTI, M. C. O.; SATO, C. A.; ROCHA, S. A.; SPAGNUOLO, R. S. Acolhimento na estratégia saúde da família: revisão integrativa. Revista Panamericana de Salud Publica, Washington, v. 35, n. 2, 2014. Disponível em: < http://www.scielosp.org/pdf/ rpsp/v35n2/a09v35n2.pdf>. Acesso em: 5 jun. 2017.

GOMES, R. Sexualidade masculina, gênero e saúde. Rio de Janeiro: Fiocruz, 2008. 
GOMES, R.; MOREIRA, M. C. N.; NASCIMENTO, E. F.; REBELlO, L. E. F. S.; COUTO, M. T.; SCHRAIBER, L. B. Os homens não vêm! Ausência e/ou invisibilidade masculina na atenção primária. Ciência \& Saúde Coletiva, Rio de Janeiro, v. 16, s. 1, p. 983-992, 2011.

MINAYO, M. C. S. Contradições e consensos na combinação de métodos quantitativos e qualitativos. In: $O$ desafio do conhecimento: pesquisa qualitativa em saúde. São Paulo: Hucitec, 2007. p. 54-76.

MOURA, E. C.; SANTOS, W.; NEVES, A. C. M.; ROMEU, G.; SCHWARZ, E. Atenção à saúde dos homens no âmbito da estratégia saúde da família. Ciência \& Saúde Coletiva, Rio de Janeiro, v. 19, p. 429-438, 2014.

SCLIAR, M. História do conceito de saúde. PHYSIS: Revista de Saúde Coletiva, Rio de Janeiro, v. 17, n. 1, p. 29-41, 2007.

SCHRAIBER, L. B.; FIGUEIREDO, W.; GOMES, R.; COUTO, M. T.; PINHEIRO, T. F.; MACHIN, R.; SILVA, G. S. N.; VALENÇA, O. Necessidades de saúde e masculinidades: atenção primária no cuidado aos homens. Cadernos de Saúde Pública, Rio de Janeiro, v. 26, p. 961-970, 2010.

SILVA, D. M.; SOUZA, T. O.; LIMA, M. V.; YARID, S. D.; SENA, E. L. S. Acessibilidade do homem aos serviços da atenção básica: uma aproximação com a bioética da proteção. Cogitare Enfermagem, Curitiba, v. 18, p. $573-8,2013$.

SILVA, P. A. S.; FURTADO, M. S.; GUILHON, A. B.; SOUZA, N. V. D. O.; DAVID, H. M. S. L. A saúde do homem na visão dos enfermeiros de uma unidade básica de saúde. Escola Anna Nery Revista de Enfermagem, Rio de Janeiro, v. 16, p. 561- 568, 2012. 
Santos, K. O.; Dos-Santos, E. M. 